\title{
Functional Aromatic Poly(1,3,4-oxadiazole-ether)s with Benzimidazole Pendants: Synthesis, Thermal and Dielectric Studies
}

\author{
Shimoga D. Ganesh, ${ }^{1}$ Vasantakumar K. Pai, ${ }^{1}$ \\ Mahadevappa Y. Kariduraganavar, ${ }^{2}$ and Madhu B. Jayanna ${ }^{3}$ \\ ${ }^{1}$ Department of Industrial Chemistry, School of Chemical Sciences, Jnana Sahyadri, Kuvempu University, Shankaraghatta, \\ Shimoga, Karnataka 577 451, India \\ ${ }^{2}$ Department of Chemistry and Center of Excellence in Polymer Science, Karnatak University, Dharwad 580 003, India \\ ${ }^{3}$ Department of Physics, Government Science College, Chitradurga, Karnataka 577501, India
}

Correspondence should be addressed to Vasantakumar K. Pai; vasantapai@gmail.com

Received 21 April 2014; Accepted 25 June 2014; Published 8 October 2014

Academic Editor: Anderson Dias

Copyright (C) 2014 Shimoga D. Ganesh et al. This is an open access article distributed under the Creative Commons Attribution License, which permits unrestricted use, distribution, and reproduction in any medium, provided the original work is properly cited.

\begin{abstract}
Poly(1,3,4-oxadiazole-ether) with reactive carboxylic acid pendants was synthesized from solution polymerization via nucleophilic displacement polycondensation among 2,5-bis(4-fluorophenyl)-1,3,4-oxadiazole (BFPOx) and 4,4'-bis(4-hydroxyphenyl) valeric acid (BHPA). Without altering the polymeric segments, benzimidazole modified poly(1,3,4-oxadiazole-ether)s were prepared by varying stoichiometric ratios of 1,2-phenylenediamine. The molecular structural characterization of these polymers was achieved by, FT-IR, NMR, TGA, elemental analysis, and analytical techniques. The weight-average molecular weight of virgin polymer with carboxylic acid functionality was determined by gel permeation chromatography (GPC) and was found to be $22400(\mathrm{Mw} / \mathrm{Mn}=$ 2.07). All the synthesized polyethers were compressed into pellets and electrical contacts were established to perform dielectric properties.
\end{abstract}

\section{Introduction}

High performance polymers are of outstanding significance as light emitting diodes, nonlinear optical devices, and photovoltaic cells $[1,2]$. Among these, polymers with heterocyclic groups, for instance, 1,3,4-oxadiazole, are very willfully studied for pronouncing electroluminescent properties [3-5] and to be used in electrochemical sensors [6, 7]. Poly(aryleneoxadiazole)s, which are of special interest for the production of advanced materials due to their high thermal oxidative stability and specific properties, are determined by the electron withdrawing nature of oxadiazole units. Aromatic polyoxadiazoles are known for their excellent thermal resistance and good hydrolytic stability; they have rigid molecules due to the delocalization of $\pi$-electrons, which makes them insoluble in organic solvents and infusible, and therefore their processing and practical use is very limited [8]. The most part of the recent research aims to obtain structurally modified poly(1,3,4-oxadiazole)s with flexible ether and sulfone linkages for good solubility in organic solvents and lower glass transition temperature, in order to allow their processing from solution, without affecting the properties that give them the status of high performance polymers; such modifications are the insertion of mesogenic substituents on aromatic rings [9], flexible bridges in the macromolecular chains, aliphatic pendants to the chain, and, more recently, the heterocyclic rings as part of the side chain of poly(1,3,4-oxadiazole-ether) [10-13].

Benzimidazoles can be easily constructed via classical synthetic route from the condensations of 1,2-phenylenediamine with carboxylic acid functional group. Indeed, polymers bearing the carboxylic acid functionality can be converted practically to benzimidazoles; polymers with various heterocyclic units are widely used and studied for 


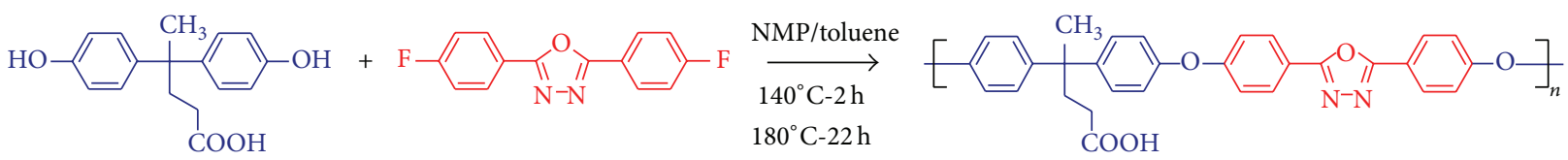

VALPOx

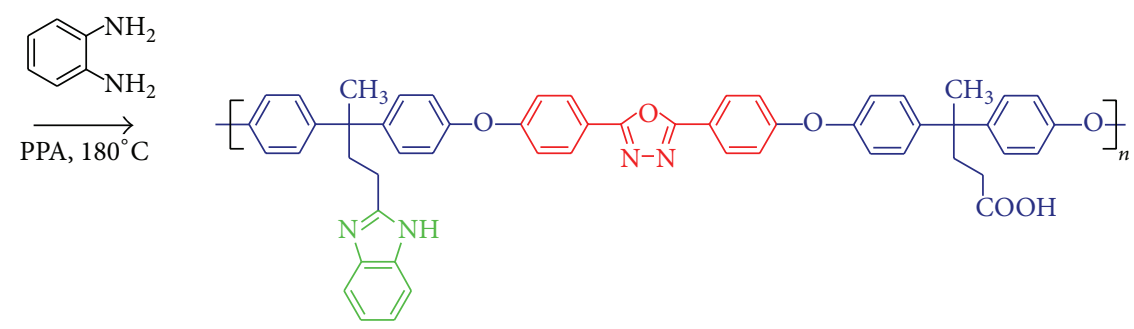

FIGURE 1: Synthetic route to prepare benzimidazole modified poly(1,3,4-oxadiazole-ether) via VALPOx polymer.

their good dielectric and pyroelectric performances $[14,15]$. Benzimidazole and 1,3,4,-oxadiazole units in main and side chain of the polymer can withstand extreme conditions without an extensive loss of properties and can be widely used in the aerospace industry, where thermal stability is a prime obligation [16]. Both heterocycles are best recognized for their admirable thermal resistance with good electrical properties $[17,18]$, due to their customary applications; various functional groups [19-22] have paid much attention to the physicochemical properties of polymeric stuff, mainly because of the unique properties of each individual. A key advantage of merging the properties of these two functional units is potential to exhibit collective thermal and dielectric properties.

The present paper describes the synthesis of a poly $(1,3,4-$ oxadiazole-ether) that comprises carboxylic acid moiety (Figure 1) and its respective benzimidazole derivatives, afforded by polyphosphoric acid condensation with $o$-phenylene diamine at different mass percentages with respect to the virgin polymer. The monomer and synthesized polymers were well characterized with various spectroscopic techniques, and the dielectric performance of the polymers was investigated.

\section{Experimental}

2.1. Materials. 4,4'-Bis(4-hydroxyphenyl) valeric acid and 4fluoro benzoic acid were purchased from Sigma-Aldrich and used as received. $N$-methyl pyrrolidinone (NMP) was purchased from Merckand purified by distillation over phosphorous pentoxide under reduced pressure. Potassium carbonate and 1,2-phenylenediamine (used after recrystallization from hot water) were purchased from HIMEDIA Chemicals. Polyphosphoric acid was purchased from Spectrochem Pvt. Ltd.; all other solvents and reagents are purchased from S.D. Fine Chem. Ltd., Mumbai, India, were of analytical grade, and were used without further purification. Double distilled water was used throughout the study.
2.2. Instrumentation. Elemental analyses were performed with a PerkinElmer PE $2400 \mathrm{CHN}$ elemental analyzer. The Fourier transform infrared (FT-IR) spectra were recorded by a Thermo Nicolet -5700, USA, spectrometer (diamond window method). The ${ }^{1} \mathrm{H} \&{ }^{13} \mathrm{C}$ NMR spectra were recorded on a Bruker Avance $400 \mathrm{MHz}$ spectrometer using tetramethylsilane (TMS) as an internal standard reference. The solidstate ${ }^{13} \mathrm{C}$-NMR spectra were recorded on a Bruker DSX-500 solid-state NMR spectrometer with a magnetic field of 7.04 T and carbon frequency of $125.77 \mathrm{MHz}$ (internal standard was glycine). Thermogravimetric analysis (TGA) was performed on a PerkinElmer Diamond TGA/DTA thermogravimetric analyzer at a heating rate of $10^{\circ} \mathrm{C} / \mathrm{min}$ in a nitrogen atmosphere. The number- and weight-average molecular weights $\left(M_{n}\right.$ and $\left.M_{w}\right)$ of VALPOx polymer were estimated by gel permeation chromatography (HP/GPC, Waters). Degassed tetrahydrofuran (THF) was used as eluent at a flow rate of $1.0 \mathrm{~mL} / \mathrm{min}$. A set of monodisperse polystyrene standards covering the range of $10^{3}-10^{7}$ was used for the molecular weight calibration.

\section{Synthesis}

3.1. Synthesis of the Monomer 2,5-Bis(4-fluorophenyl)-1,3,4oxadiazole (BFPOx). Method was adapted from the literature [23]. To a pulverized mixture of 4-fluorobenzoic acid $(14.05 \mathrm{~g}$, $10 \mathrm{mmol})$ and hydrazine sulphate $(6.574 \mathrm{~g}, 5 \mathrm{mmol}), 125 \mathrm{~g}$ of polyphosphoric acid was added under a moisture free nitrogen atmosphere, into a round-bottom flask equipped with a magnetic stirrer and a condenser. The reaction system was then evacuated and filled with nitrogen for three times to remove air and moisture. The solution was heated to $150^{\circ} \mathrm{C}$ with stirring under the protection of moisture free nitrogen atmosphere and maintained at this temperature for $6 \mathrm{~h}$, and then the reaction temperature was slowly increased to $200^{\circ} \mathrm{C}$ over $3 \mathrm{~h}$ to affect the ring closure. The solution was allowed to further react for an additional $1 \mathrm{~h}$ at this temperature until no more gas release was observed. The reaction mass was then cooled to about $60^{\circ} \mathrm{C}$ and poured into $500 \mathrm{~mL}$ 
of ice cold distilled water with stirring. The white fibrous material obtained was collected by filtration and washed with saturated sodium bicarbonate solution (to remove unreacted 4-fluorobenzoic acid) and finally washed several times with hot water until the filtrate was neutral. The purification of the crude product was done by recrystallization from a $95 \%$ ethanol/THF (90/10) mixture twice, which generated $10.8 \mathrm{~g}$ of the pure white crystals with a yield of 85\%. MP: 203.2$203.8^{\circ} \mathrm{C} .{ }^{19} \mathrm{~F}$ NMR $\left(\delta\right.$, DMSO- $\left.d_{6}\right):-107.28$ (s, 2F, para to Ox). ${ }^{1} \mathrm{H}$ NMR $\left(\delta\right.$, DMSO- $\left.d_{6}\right): 7.43-7.48(\mathrm{~m}, 4 \mathrm{H}), 8.15-8.18$ $(\mathrm{m}, 4 \mathrm{H}),{ }^{13} \mathrm{C}$ NMR $\left(\delta, \mathrm{DMSO}-d_{6}\right): 165.38$ (F attached to C), 163.28 (2C, Ox), 162.90 (F attached to C), $129.42 \& 129.33$ (2C, attached to oxadiazole), $119.97 \& 119.94$ (4C, ortho to $\mathrm{Ox}$ ), $116.76 \& 116.51$ (4C, meta to $\mathrm{Ox})$.

MS: $259.0\left(\mathrm{MH}^{+}\right)$; calcd for $\mathrm{C}_{14} \mathrm{H}_{8} \mathrm{~F}_{2} \mathrm{~N}_{2} \mathrm{O}$, 258.36. Anal. Calcd: C, 65.12; H, 3.12; F, 14.7; N, 10.85; O, 6.20. Found: C, 65.04; H, 3.01; N, 10.68. FT-IR (diamond window): $1652(\mathrm{C}=\mathrm{N}$ of Ox ring), 1560, 1504, 1422, 1364, 1320, 1214, 1104, 1038, 992, $845,821,779,749,709 \mathrm{~cm}^{-1}$.

3.2. Synthesis of (VALPOx) Poly(1,3,4-oxadiazole-ether). The synthesis of VALPOx with active free carboxylic acid groups was achieved from the nucleophilic displacement reaction of oxadiazole-activated bis(fluoride) monomer with 4,4' -bis(4hydroxyphenyl) valeric acid.

A typical synthesis of this polymer was conducted in a three-neck flask equipped with a nitrogen inlet, stirrer, DeanStark trap, and condenser.

The flask was charged with 2,5-bis(4-fluorophenyl)-1,3,4oxadiazole, $0.2582 \mathrm{~g}$ ( $1 \mathrm{mmol}), 0.2684 \mathrm{~g}$ ( $1 \mathrm{mmol}), \mathrm{K}_{2} \mathrm{CO}_{3}$ $(0.2903 \mathrm{~g}, 2.1 \mathrm{mmol})$, N-Methyl pyrollidine $(10 \mathrm{~mL})$, and toluene $(10 \mathrm{~mL})$; the flask was purged with moisture free nitrogen three times. The reaction mixture was then heated to $120^{\circ} \mathrm{C}$ for $2 \mathrm{~h}$ until the toluene was all condensed in the DeanStark trap. Upon dehydration, the polymerization was heated to $180^{\circ} \mathrm{C}$ for $22 \mathrm{~h}$. The cooled viscous reaction mixture was diluted with $5 \mathrm{~mL}$ of NMP and then dropped into $300 \mathrm{~mL}$ of demineralised water containing $10 \%$ hydrochloric acid. The precipitated polymer was repeatedly washed with excess of water and dried in vacuum at $60^{\circ} \mathrm{C}$.

Yield: 85\%; FT-IR (diamond window, $\left.\mathrm{cm}^{-1}\right) 1708(\mathrm{C}=\mathrm{O}$, sym.), 1585 (C=O, asym.), 1504 ( $-\mathrm{C}=\mathrm{N}$, sym.), 1488, 1243 ($\mathrm{C}-\mathrm{O}-\mathrm{C}), 1070$ (C-O, oxadiazole ring). ${ }^{1} \mathrm{H}$ NMR (400 MHz, DMSO- $\left.d_{6}\right): \delta=1.44-1.60(\mathrm{~m}, 3 \mathrm{H}), 1.97-2.02(\mathrm{~m}, 2 \mathrm{H}), 2.27-$ 2.37 (d, 2H), 6.63-6.69 (br s, 1H), 6.91-7.05 (br s, 4H), 7.15 (br s, $4 \mathrm{H}), 7.02-7.22(\mathrm{~m}, 1 \mathrm{H}), 7.26$ (br s, $2 \mathrm{H}), 7.45(\mathrm{~m}, 1 \mathrm{H}), 8.06-$ 8.08 (br s, 3H), 8.16-8.19 (m, 1H) 12.05 (br s, $1 \mathrm{H}) .{ }^{13} \mathrm{C}$ NMR (125 MHz, solid state): $\delta=30.42,35.78,45.13,121.13,129.53$, $134.37,143.00,144.21,151.74,162.90,171.27,176.52,177.46$.

3.3. Synthesis of Benzimidazole Modified VALPOx Polymer. A direct synthesis of a modified VALPOx polyether with 30 mass \% 1,2-phenylenediamine (VALPOx-B-30) is discussed. In a $100 \mathrm{~mL}$, three-neck flask equipped with a mechanical stirrer and a nitrogen inlet/outlet, finely powdered $1.0 \mathrm{~g}$ $(9.0 \mathrm{mmol})$ of VALPOx and $0.3 \mathrm{~g}$ of 1,2 -phenylenediamine were added and stirred by adding $20 \mathrm{~g}$ of polyphosphoric acid. The reaction system was then evacuated and filled with nitrogen for three times to remove air and moisture. The reaction mixture was stirred at $120^{\circ} \mathrm{C}$ for $1 \mathrm{~h}$ until complete dissolution of the polymer and 1,2-phenylenediamine; then temperature was slowly raised to $150^{\circ} \mathrm{C}$ for a period of $12 \mathrm{~h}$. The reaction mixture was cooled to about $60-70^{\circ} \mathrm{C}$ and poured in to $500 \mathrm{~mL}$ ice cold distilled water with proper stirring, The dark pinkish brown fibrous material separated was collected by filtration and washed several times with water and finally washed with hot water until the filtrate was neutral. The resulting dark brown polymer VALPOx-B-30 was dried under vacuum at $60^{\circ} \mathrm{C}$ for $24 \mathrm{~h}$.

Yield: 80\%; FT-IR (diamond window, $\left.\mathrm{cm}^{-1}\right) 3394(\mathrm{~N}-$ H), 1600 (-C=N, sym), 1488, 1243 (-C-O-C), 1069 (C-O, oxadiazole ring). ${ }^{13} \mathrm{C}$ NMR (125 MHz, solid state): $\delta=62.89$, $65.25,71.60,72.52,74.93,84.47,88.99,104.37,118.87,128.98$, $153.54,156.89,163.21$.

A similar procedure was followed for the synthesis of polymers VALPOx-B-10 and VALPOx-B-20. For example,VALPOx-B-10 describes the VALPOx polymer that incorporates 10 mass \% of 1,2-phenylenediamine.

\section{Results and Discussion}

4.1. Synthesis and Characterization. The synthesis of new polymer VALPOx with active carboxylic acid moiety was achieved via conventional aromatic nucleophilic substitution polymerization technique from $4,4^{\prime}$-bis(4-hydroxyphenyl) valeric acid and 2,5-bis(4-fluorophenyl)-1,3,4-oxadiazole; the polycondensation was carried out at elevated temperature in $\mathrm{NMP} /$ toluene azeotrope in presence of anhydrous pulverised potassium carbonate as catalyst. The carboxylic acid in the virgin polymer is successfully converted to benzimidazole pendants via polyphosphoric acid condensation route. The amount of 1,2-phenylenediamine with respect to VALPOx varied as 10, 20, and 30 mass $\%$, and the polymers thus obtained were designated as VALPOx-B-10, VALPOx-B-20, and VALPOx-B-30, respectively. The incorporation of benzimidazole moiety in polymer was confirmed via FTIR spectroscopy (diamond window method) in the range of 400$4000 \mathrm{~cm}^{-1}$; in each scan, the amount of well-grounded sample was kept constant $(1 \mathrm{mg})$ in order to estimate the changes in the intensities of the characteristic peaks with respect to the amount of 1,2-phenylenediamine; the peak at $1070 \mathrm{~cm}^{-1}$ was assigned to $\mathrm{C}-\mathrm{O}$ stretching of oxadiazole and benzimidazole modified poly(1,3,4-oxadiazole-ether) shows $3394 \mathrm{~cm}^{-1}$ peak for N-H stretching; NMR spectroscopic studies of synthesized polymers are in agreement with the proposed structure. Signal broadening of the ${ }^{1} \mathrm{H}$ NMR spectrum of the polymer VALPOxwas due to polymerization and is presented in Supplementary Material (See Supplementary Material available online at http://dx.doi.org/10.1155/2014/790702). The signals resonated at $12.05 \mathrm{ppm}$ were assigned to carboxylic acid protons, and signals at the range of 2.00 and $2.34 \mathrm{ppm}$ were assigned to methylene protons, indicating the $4,4^{\prime}$ bis(4-hydroxyphenyl) valeric acid moiety introduced successfully, indicating the formation of polyether (VALPOx) with carboxylic acid pendants; further signal at $174.50 \delta$ in ${ }^{13} \mathrm{C}$ NMR spectra (see Supplementary Material) confirms the 


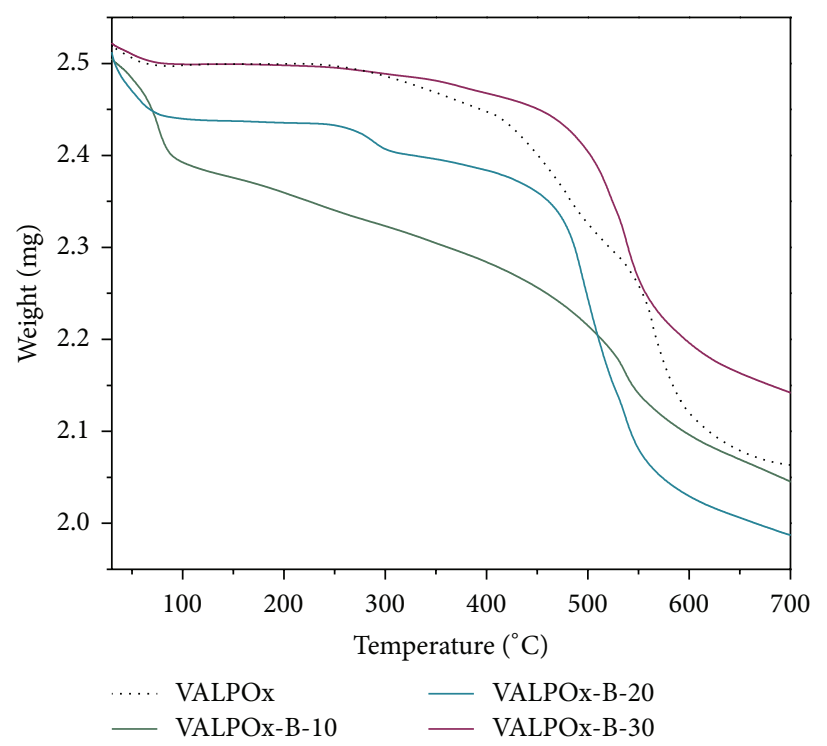

FIGURE 2: TGA plot of poly(1,3,4-oxadiazole-ether)s at a heating rate of $10^{\circ} \mathrm{C} / \mathrm{min}$ under a nitrogen atmosphere.

TABLE 1: Kinetic and thermodynamic parameters of polyethers.

\begin{tabular}{lccccr}
\hline Samples* & Decomposition range $\left({ }^{\circ} \mathrm{C}\right)$ & $\begin{array}{c}E_{a} \\
(\mathrm{~kJ} / \mathrm{mol}) \\
\times 10^{-3}\end{array}$ & $\ln A$ & $\begin{array}{c}\Delta H \\
(\mathrm{~kJ} / \mathrm{mol})\end{array}$ & $\begin{array}{c}\Delta S \\
\mathrm{~kJ} / \mathrm{K}\end{array}$ \\
\hline P & $350-640$ & 1.582 & -9.93 & -6.39285 & -161.624 \\
$\mathrm{P}-\mathrm{BJ}-10$ & $410-610$ & 1.256 & -10.17 & -6.52982 & -161.222 \\
P-B-20 & $420-590$ & 2.919 & -9.18 & -6.46377 & -161.298 \\
P-B-30 & $422-610$ & 1.953 & -9.68 & -6.56409 & -161.563 \\
\hline
\end{tabular}

${ }^{*} \mathrm{P}=$ VALPOx, P-B-10 = VALPOx-B-10, P-B-20 = VALPOx-B-20, and P-B-30 = VALPOx-B-30.

carboxylic acid carbon and two methylene carbons at $29.87 \delta$ and $36.15 \delta$. The insertion of oxadiazole unit is revealed by the signal at $165.40 \delta$, indicating the oxadiazole unit carbons attached to phenyl rings in polymer chain. Due to insolubility of benzimidazole substituted polymers, solidstate ${ }^{13} \mathrm{C}$ NMR was recorded in comparison to VALPOx polymer which was presented in Supplementary Material. It gave sufficient information for successful incorporation of pendant benzimidazole into the polymer. Solid-state ${ }^{13} \mathrm{C}$ NMR of VALPOx exhibits broad peak around 176.5177.4 ppm which corresponds to the carbonyl carbon of the carboxylic acid; peaks at 162.9-172.9 ppm were assigned to carbons of oxadiazole ring; a broad signal at 121.1-134.3 ppm and 30.4-45.1 ppm corresponds to aromatic and aliphatic regions of the polymer chain, respectively; aromatic carbons attached to the oxadiazole unit was observed at 143.0$151.7 \mathrm{ppm}$. The deshielded aliphatic signals and absence of peak around 176.5-177.4 ppm suggest the successful complete conversion of pendant carboxylic acid to benzimidazole at maximum stoichiometric ratio (VALPOx-B-30). The molecular weight of VALPOx polymer was determined by GPC with polystyrene as the standard and THF as the eluent, showed $M_{w}$ of 22400 with polydispersity 2.07. The VALPOx polymer was soluble in THF, DMAc, DMSO, and NMP at ambient temperature but the solubility of benzimidazole modified polymers was poor in aforementioned solvents as benzimidazole content upsurges in the polymer. These modified poly(1,3,4-oxadiazole-ether)s were compressed into pellets for further AC electrical studies.

4.2. Thermal Analysis. Thermogravimetric analyses (TGAs) were performed for all the polymers and the results were presented in Figure 2. Poly(1,3,4-oxadiazole-ether) containing carboxylic acid showed a high-temperature stability with an onset of decomposition at $250^{\circ} \mathrm{C}$. Therefore, polymer was modified in bulk at $150^{\circ} \mathrm{C}$ under nitrogen to acquire the benzimidazole bearing poly(1,3,4-oxadiazole-ether)s. These polymers showed high-temperature stability up to $610^{\circ} \mathrm{C}$, due to 1,3,4-oxadiazole unit in the main chain with benzimidazole side groups. The moisture loss is observed before $150^{\circ} \mathrm{C}$. Another major steep weight loss range of $240-320^{\circ} \mathrm{C}$ was noticed in VALPOx, VALPOx-B-10, and VALPOx-B-20 and was assigned to the decomposition carboxylic acid groups from polymer chain, and also we cannot neglect the ionic interactions of carboxylic acid groups with the benzimidazole moieties. The main polymeric backbone degradation step in case of benzimidazole modified VALPOx polymers can be accounted and is in the range of $420-610^{\circ} \mathrm{C}$, while VALPOx polymer shows degradations stability in the range $350-640^{\circ} \mathrm{C}$ owing to the presence of carboxylic acid groups.

Kinetic and thermodynamic parameters were determined using Broido's method [24] and tabulated in Table 1. Plots 


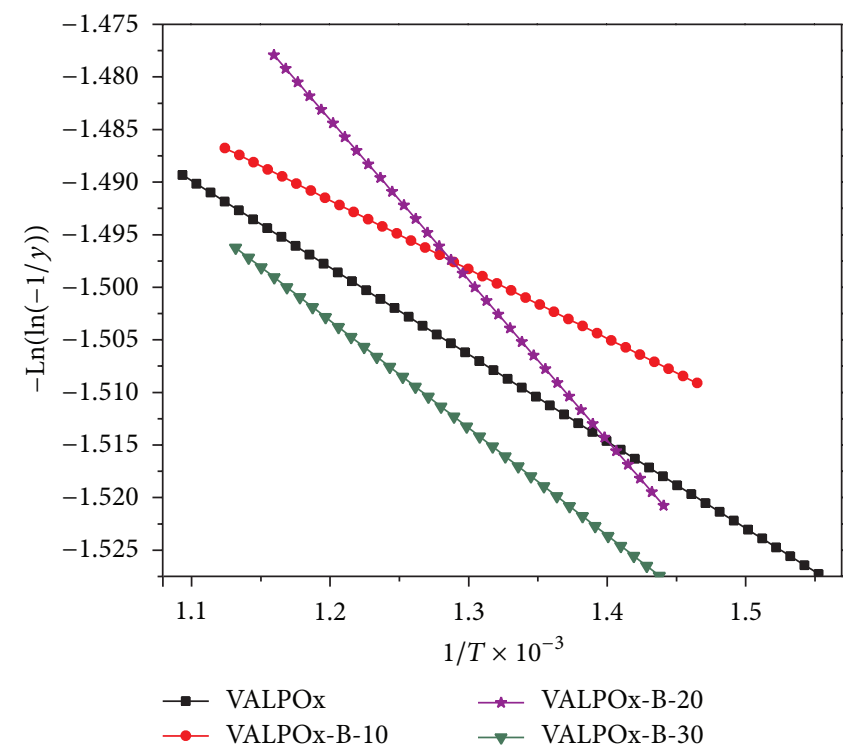

Figure 3: Plots of $-\operatorname{Ln}(\ln (-1 / y))$ versus $1 / T \times 10^{-3}$ for the decomposition step in the range $350-640^{\circ} \mathrm{C}$ of VALPOx, VALPOx-B-10, VALPOxB-20, and VALPOx-B-30 polymer sample.

of $-\operatorname{Ln}(\ln (-1 / Y))$ versus $1 / T$ (where $Y$ is the fraction of the compound undecomposed) were developed for the decomposition segment. From the plot (Figure 3) the activation energy $\left(E_{a}\right)$ and frequency factor $(\ln A)$ were evaluated. The enthalpy $(\Delta H)$, entropy $(\Delta S)$, and free energy $(\Delta G)$ have been calculated.

4.3. AC Electrical Measurements. Finely powdered polymer samples were compressed into pellets of thickness in the range of $0.5-0.6 \mathrm{~mm}$ and subjected to the dielectric measurements; Sandwiched polymer samples between two silverplated stainless steel electrodes were analysed by impedance analyzer model HIOKI 3352-50 HiTESTER Version 2.3. Silver paint (ELTECKS preparation number 1228-C) was coated on both of the flat exteriors of the pressed tablet and the electrical contacts were made using the same silver paint to the silver electrodes. The electrical contacts were checked to verify the ohmic connection. The measurements were carried out at room temperature in between the $50 \mathrm{~Hz}-5 \mathrm{MHz}$. The capacitance value $(C)$ and ac conductance $(G)$ were directly obtained from the apparatus. The dielectric constant $\left(\varepsilon^{\prime}\right)$ and ac conductivity $\left(\sigma_{\mathrm{ac}}\right)$ values are calculated using (1) and (2), respectively:

$$
\begin{gathered}
\varepsilon^{\prime}=\frac{C_{P} d}{\varepsilon_{o} A}, \\
\sigma_{\mathrm{ac}}=\frac{G d}{A},
\end{gathered}
$$

where " $d$ " is the thickness of the polymer pellet and " $A$ " is the cross-section area and $\varepsilon_{o}$ is the permittivity of the free space. All these measurements were performed under dynamic vacuum.
4.4. Frequency Dependence of Dielectric Constant $\left(\varepsilon^{\prime}\right)$ and Dielectric Loss $(\tan \delta)$. The variation of dielectric constant versus frequency at room temperature was plotted in Figure 4. The typical decrease in the $\varepsilon^{\prime}$ is observed as polyethers generally follow [25]; at lower frequencies $(<100 \mathrm{~Hz})$ there is an increasing contribution to the dielectric constant; this is because at very low frequencies dipoles follow the field. The dielectric constant remains fairly constant at low frequency region; such behavior is attributed to presence of frozen dipoles slowly attaining freedom of rotation at higher frequencies; the charge carriers may migrate via dielectric and get trapped against a defect site; they induce opposite charge in their vicinity; as a result of this motion of charge carriers slowed down and decrease in the $\varepsilon^{\prime}$ is observed [26]. Minor upsurge in the $\varepsilon^{\prime}$ is witnessed more by VALPOx-B30 than the virgin VALPOx polymer, owing to the maximal benzimidazole moieties in the polymer segments.

Plot of loss factor $(\tan \delta)$ versus $\log$ (frequency) is shown in Figure 5. In accordance with the plot, dielectric loss $(\tan \delta)$ decreases exponentially with increase of frequency up to $4 \mathrm{kHz}$ and attains the constant value due to interfacial polarization. This results supports the view that frequency dependence dielectric loss could be explained using near constant loss (NCL) model $[27,28]$.

4.5. Frequency Dependence of ac Conductivity $\left(\sigma_{a c}\right)$. The frequency dependence of the ac conductivity for VALPOx and benzimidazole modified VALPOx polymers are shown in Figure 6. The plot reveals that conductivity increases with increase of frequency as well as benzimidazole content in the VALPOx; this is due to frequent charge motion within the sample. As the polymer is modified by the benzimidazole moiety, increase in the $\sigma_{\mathrm{ac}}$ is noticed; increased 


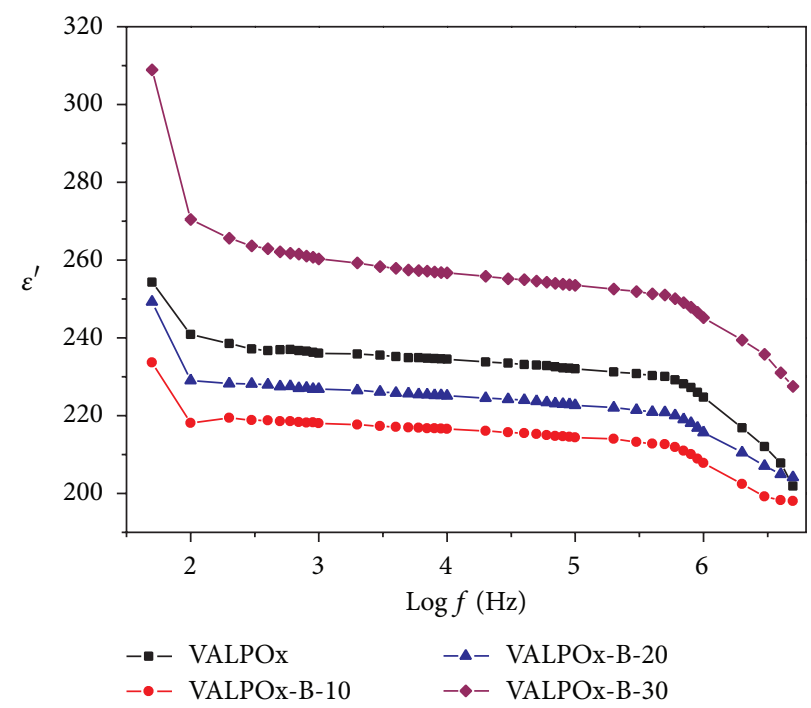

FIGURE 4: Room temperature variation of dielectric constant $\left(\varepsilon^{\prime}\right)$ with $\log$ (frequency) of VALPOx and benzimidazole modified VALPOx polymers.

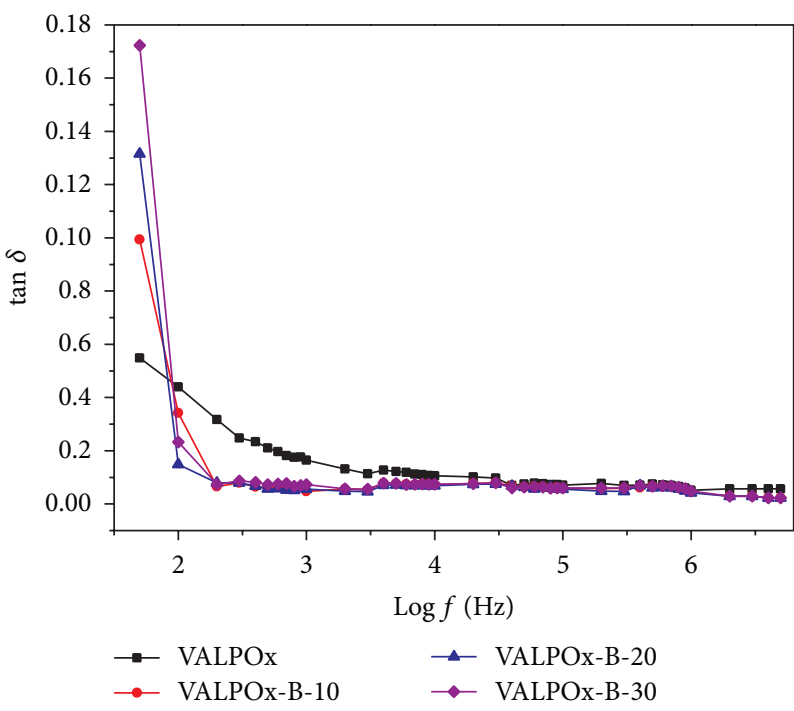

FIGURE 5: Room temperature variation of loss tangent on log (frequency) for VALPOx and benzimidazole modified VALPOx polymers.

benzimidazole units are expected to interact with $1,3,4$ oxadiazole segments in the polymeric chain; benzimidazole modification converts the parent polymer structure into free hydrogen depleted carbon network, and as a result ac field of sufficiently higher frequency may cause the net polarization of the polymer, which will make the net polarization in a given field larger and hence the dielectric constant will be higher. which is out of phase with the field. This results in increase of conductivity at higher frequencies.

\section{Conclusion}

Poly(1,3,4-oxadiazole-ether)s with pendant benzimidazole units were synthesized and characterized; it was demonstrated that good thermally stable polymeric stuff can be synthesized from the pendant carboxylic acid functional poly(1,3,4-oxadiazole-ether) (VALPOx); reactive pendant carboxylic acid group is exploited to hold the benzimidazole moieties, by polyphosphoric acid condensation. These polymers with benzimidazole and oxadiazole heterocycles exhibit remarkable thermal stability with decomposition temperature above $410^{\circ} \mathrm{C}$. Frequency dependence ac conductivity has been found to support the nearly constant loss (NCL) model in isothermal condition at room temperature. The dielectric constant $\varepsilon^{\prime}$ and dielectric loss $(\tan \delta)$ depend on frequency up to $4 \mathrm{kHz}$ and are nearly constant beyond. In summary, these polymers with significant properties have been demonstrated to be a robust yet flexible class of materials with potential applications in microelectronics as sensory materials and high operating frequency devices. 


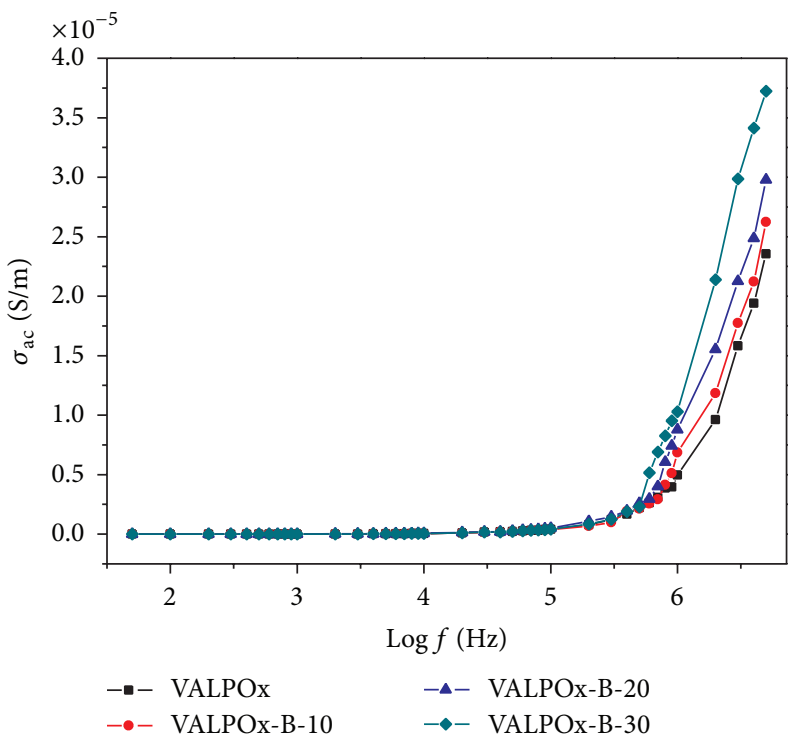

FIGURE 6: Room temperature variation of AC conductivity with $\log$ (frequency) for VALPOx and benzimidazole modified VALPOx polymers.

\section{Conflict of Interests}

It is to state that neither authors nor their institution has financial or other relationships with any organization or people that may influence the author's work. Authors are not being paid by any organization or agency related with the product. There is no conflict of interests to be declared.

\section{Acknowledgments}

The authors gratefully acknowledge Indian Institute of Science, STIC, and SICART for providing NMR, TGA, and GPC measurements.

\section{References}

[1] Q. Liu, M. Wang, C. Li et al., "Polymer photovoltaic cells based on polymethacrylate bearing semiconducting side chains," Macromolecular Rapid Communications, vol. 33, no. 24, pp. 2097-2102, 2012.

[2] X. Gong, J. C. Ostrowski, D. Moses, G. C. Bazan, and A. J. Heeger, "High-performance polymer-based electrophosphorescent light-emitting diodes," Journal of Polymer Science B: Polymer Physics, vol. 41, no. 21, pp. 2691-2705, 2003.

[3] J. A. Mikroyannidis, K. M. Gibbons, A. P. Kulkami, and S. A. Jenekhe, "Poly(fluorenevinylene) copolymers containing bis(phenyl)oxadiazole and triphenylamine moieties: synthesis, photophysics, and redox and electroluminescent properties," Macromolecules, vol. 41, no. 3, pp. 663-674, 2008.

[4] Y. Z. Lee, X. Chen, M. C. Chen, S. A. Chen, J. H. Hsu, and W. Fann, "White-light electroluminescence from soluble oxadiazole-containing phenylene vinylene ether-linkage copolymer," Applied Physics Letters, vol. 79, no. 3, pp. 308-310, 2001.

[5] Q. Yang, H. Jin, Y. Xu et al., "Electroluminescent block copolymers containing oxadiazole and thiophene via ATRP," Journal of
Polymer Science A: Polymer Chemistry, vol. 48, no. 24, pp. 56705678,2010

[6] E. Hamciuc, M. Bruma, T. Köpnick, Y. Kaminorz, and B. Schulz, "Synthesis and study of new silicon-containing polyoxadiazoles," Polymer, vol. 42, no. 5, pp. 1809-1815, 2001.

[7] N. Nasirizadeh, H. R. Zare, A. R. Fakhari, H. Ahmar, M. R. Ahmadzadeh, and A. Naeimi, "A study of the electrochemical behavior of an oxadiazole derivative electrodeposited on multiwall carbon nanotube-modified electrode and its application as a hydrazine sensor," Journal of Solid State Electrochemistry, vol. 15, no. 11-12, pp. 2683-2693, 2011.

[8] B. Schulz, M. Bruma, and L. Brehmer, "Aromatic poly(1, 3, 4Oxadiazoe)s as advanced materials," Advanced Materials, vol. 9, no. 8, pp. 601-613, 1997.

[9] C. Tsai and Y. Chen, "Thermotropic liquid-crystalline poly(oxadiazole)s with poly(methylene) spacers: preparation and extraordinary odd-even effect," Journal of Polymer Science A: Polymer Chemistry, vol. 40, no. 3, pp. 293-301, 2002.

[10] M. D. Iosip, M. Bruma, I. Ronova, M. Szesztay, and P. Müller, "Compared properties of related aromatic poly $(1,3,4$ oxadiazole-amide)s," European Polymer Journal, vol. 39, no. 10, pp. 2011-2021, 2003.

[11] L. W. Frost, G. M. Bower, J. H. Freeman, H. A. Burgman, E. J. Traynor, and C. R. Ruffing, "Benzimidazole- and oxadiazolemodified aromatic polyimides," Journal of Polymer Science A-1: Polymer Chemistry, vol. 6, no. 1, pp. 215-233, 1968.

[12] R. G. Tasaganva, M. Y. Kariduraganavar, and S. R. Inamdar, "Synthesis and nonlinear optical properties of polyurethanes containing nitro-substituted 1,3,4-oxadiazole chromophores," Synthetic Metals, vol. 159, no. 17-18, pp. 1812-1819, 2009.

[13] S. M. Tambe, A. A. Kittur, S. R. Inamdar, G. R. Mitchell, and M. Y. Kariduraganavar, "Synthesis and characterization of thermally stable second-order nonlinear optical side-chain polyimides containing thiazole and benzothiazole push-pull chromophores," Optical Materials, vol. 31, no. 6, pp. 817-825, 2009.

[14] C. Y. Iguchi, W. N. dos Santos, and R. Gregorio Jr., "Determination of thermal properties of pyroelectric polymers, copolymers 
and blends by the laser flash technique," Polymer Testing, vol. 26, no. 6, pp. 788-792, 2007.

[15] P. Vasudevan, H. S. Nalwa, K. L. Taneja, and U. S. Tewari, "Pyroelectricity in thiourea formaldehyde polymer," Journal of Applied Physics, vol. 50, no. 6, pp. 4324-4326, 1979.

[16] B. Sillion, "Aromatic and heterocyclic polymers-what future?" High Performance Polymers, vol. 11, no. 4, pp. 417-436, 1999.

[17] M. Damaceanu, R. Rusu, V. Musteata, and M. Bruma, "Dielectric behavior of thin films made from poly(oxadiazolenaphthylimide)s," Soft Materials, vol. 9, no. 1, pp. 44-63, 2010.

[18] R. Twieg, T. Matray, and J. L. Hedrick, "Poly(aryl ether benzimidazoles)," Macromolecules, vol. 29, no. 23, pp. 7335-7341, 1996.

[19] M. A. Hussein, A. M. Asiri, and K. I. Aly, "New polyamides and polyoxazoles based on diphenyl ether segments in the polymers' backbone," International Journal of Polymeric Materials and Polymeric Biomaterials, vol. 61, no. 2, pp. 154-175, 2012.

[20] T. Ivan, L. Vacareanu, and M. Grigoras, "Synthesis of poly(arylene vinylene)s containing carbazole, triphenylamine, and phenothiazine rings in the backbone by cascade suzukiheck reactions," International Journal of Polymeric Materials and Polymeric Biomaterials, vol. 62, no. 5, pp. 270-276, 2013.

[21] L. Ravikumar, I. Pradeep, T. Thangaiyan, R. Mohan, and J. Balachandran, "Synthesis, characterization, and conducting properties of poly(thiourea azomethines)," International Journal of Polymeric Materials and Polymeric Biomaterials, vol. 61, no. 4, pp. 288-299, 2012.

[22] L. Ravikumar and R. Saravanan, "Synthesis of soluble, curable, and thermally stable aromatic polyamides bearing thiourea and pendent 4-pyridylformylimino groups," International Journal of Polymeric Materials and Polymeric Biomaterials, vol. 61, no. 13, pp. 1050-1064, 2012.

[23] C. Hamciuc, E. Hamciuc, M. Bruma, M. Klapper, T. Pakula, and A. Demeter, "New aromatic polyethers containing phenylquinoxaline and 1,3,4-oxadiazole rings," Polymer, vol. 42, no. 14, pp. 5955-5961, 2001.

[24] A. Broido, "A simple, sensitive graphical method of treating thermogravimetric analysis data," Journal of Polymer Science A2: Polymer Physics, vol. 7, no. 10, pp. 1761-1773, 1969.

[25] C. Hamciuc, E. Hamciuc, A. M. Ipate, and L. Okrasa, "Copoly(1,3,4-oxadiazole-ether)s containing phthalide groups and thin films made therefrom," Polymer, vol. 49, no. 3, pp. 681690, 2008.

[26] L. A. Dissado and R. M. Hill, "Anomalous low-frequency dispersion. Near direct current conductivity in disordered lowdimensional materials," Journal of the Chemical Society, Faraday Transactions 2: Molecular and Chemical Physics, vol. 80, no. 3, pp. 291-319, 1984.

[27] H. M. El-Mallah, "AC electrical conductivity and dielectric properties of perovskite $(\mathrm{Pb}, \mathrm{Ca}) \mathrm{TiO}_{3}$ ceramic," Acta Physica Polonica A, vol. 122, no. 1, pp. 174-179, 2012.

[28] A. Rivera, C. León, J. Sanz, J. Santamaria, C. T. Moynihan, and K. L. Ngai, "Crossover from ionic hopping to nearly constant loss in the fast ionic conductor $\mathrm{Li}_{0.18} \mathrm{La}_{0.61} \mathrm{TiO}_{3}$," Physical Review BCondensed Matter and Materials Physics, vol. 65, no. 22, Article ID 224302, pp. 2243021-2243026, 2002. 

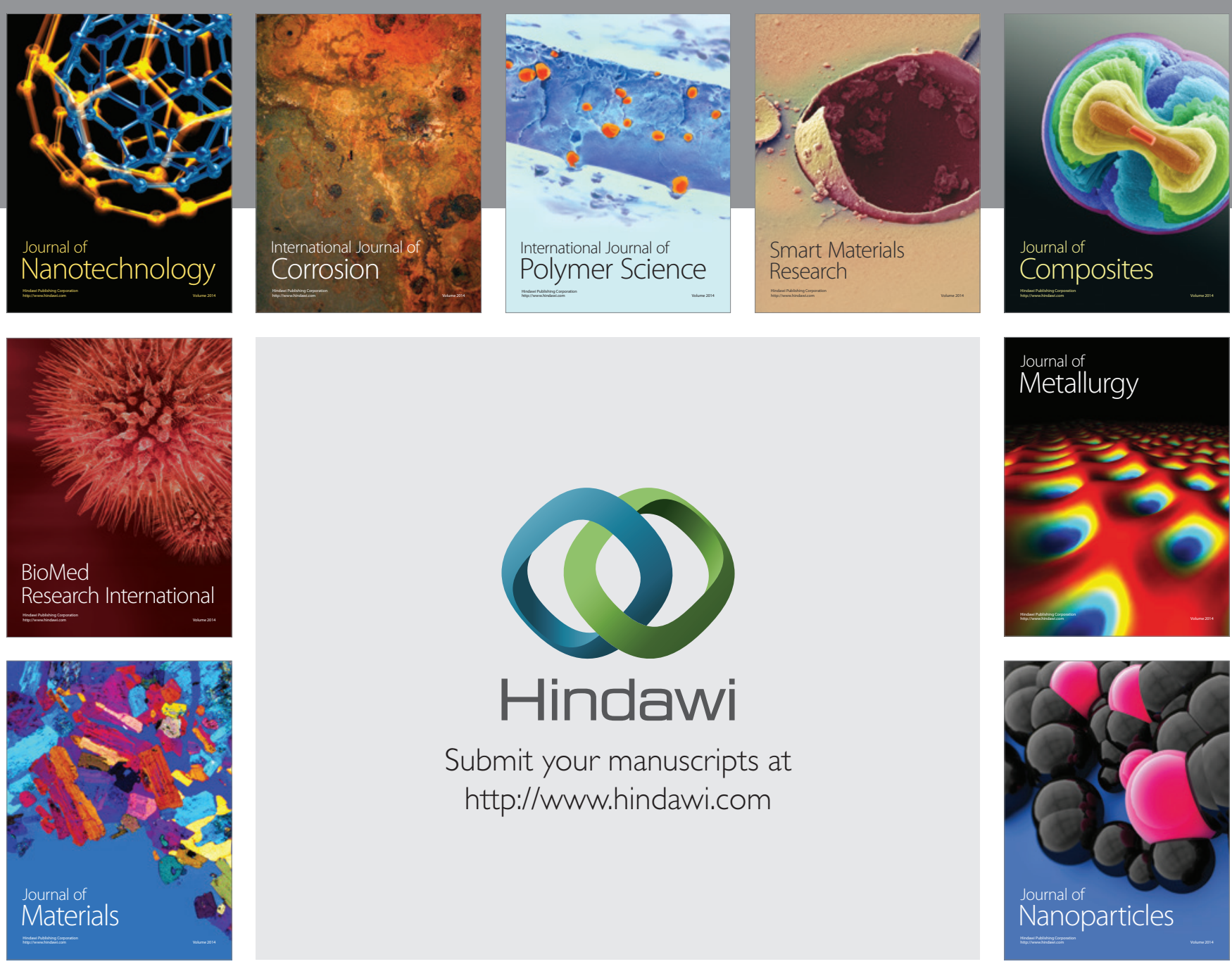

Submit your manuscripts at http://www.hindawi.com
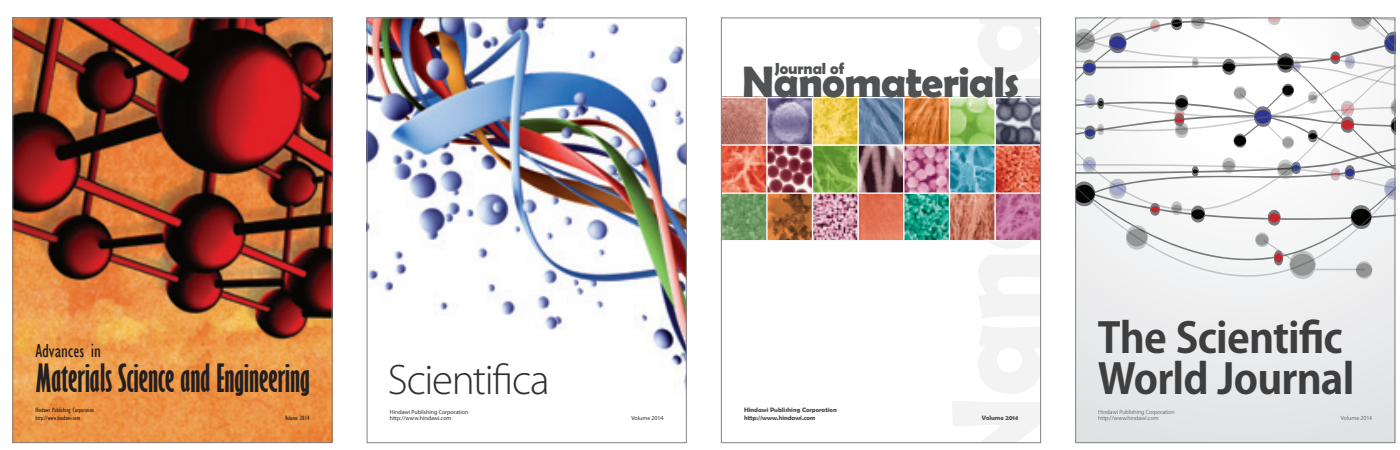

\section{The Scientific World Journal}
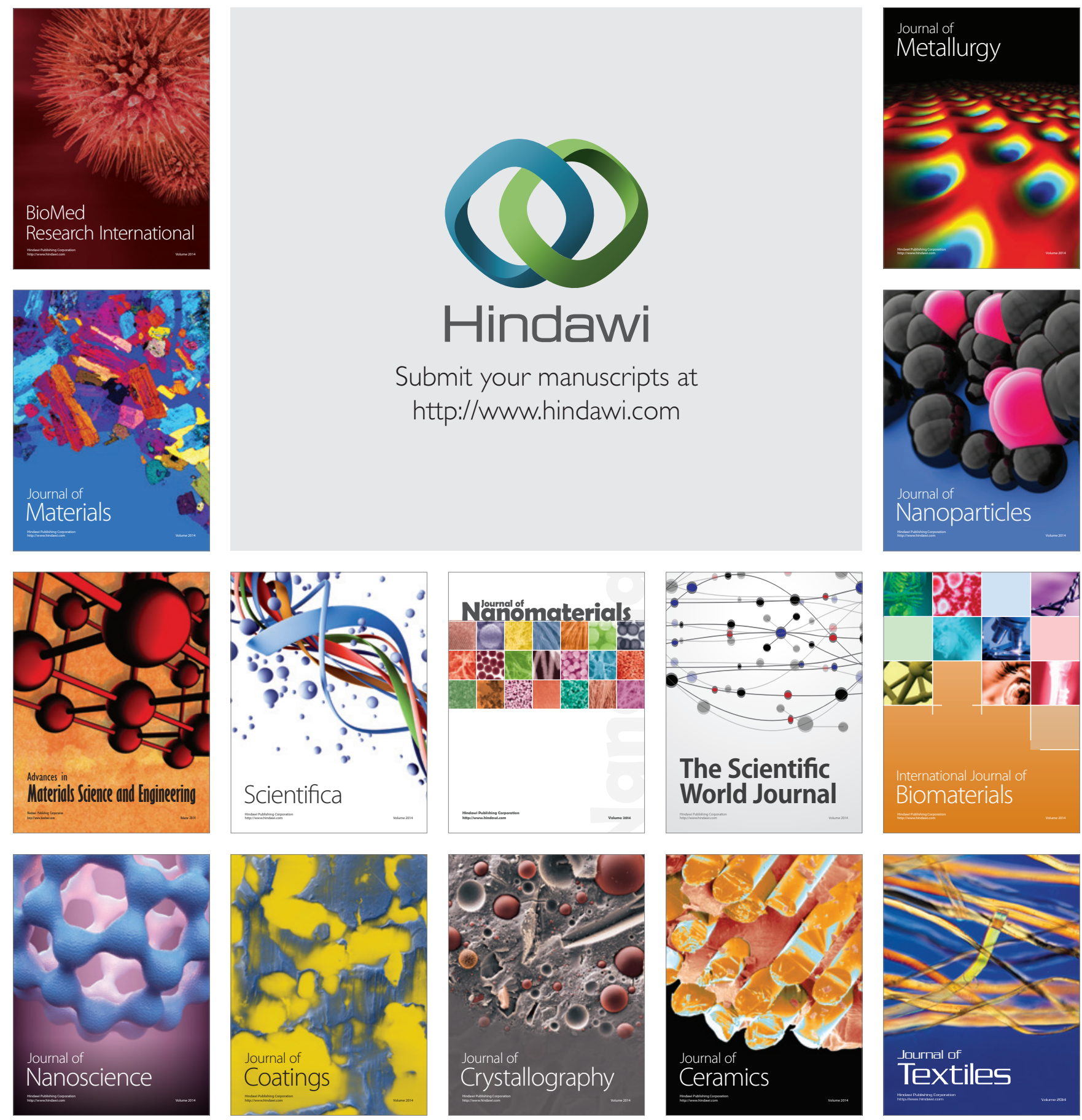